PROCEEDINGS OF THE NUTRITION SOCIETY

A Workshop of the Stratford Executive Group of the Nutrition Society was held at the Metropole Hotel, Birmingham on 15/16 November 1995

\title{
Nutrition in the undergraduate medical curriculum
}

\author{
BY A. A. JACKSON (CONVENOR) \\ ON BEHALF OF THE STRATFORD EXECUTIVE GROUP* \\ Institute of Human Nutrition, University of Southampton, Bassett Crescent East, \\ Southampton SO16 7PX
}

The Stratford Executive Group (SEG) was formed following a meeting in November 1993, organized by the Rank Department of Human Nutrition, Glasgow University, to discuss the place of nutrition in the undergraduate medical curriculum. At that time, it anticipated The Core Curriculum for Nutrition in the Education of Health Professionals (Department of Health, 1994b) which was launched 1 year later by the National Nutrition Task Force. This document would present a particular challenge for the introduction of training in nutrition in the undergraduate medical curriculum. If advantage were to be taken of this unique opportunity for nutrition to become an established part of medical undergraduate training, activities would need to be planned and coordinated. The SEG sought to maintain continuity of effort in the interim. The Nutrition Society agreed to foster the activities of the SEG, whose activities were endorsed by the Committee on Medical Aspects of Food Policy (COMA).

In order to plan sensibly for the future, the SEG convened a workshop 1 year after the presentation of the Department of Health (1994b) document on the core curriculum on nutrition, in order to benefit from the experience of those who were directly involved in the teaching of nutrition to medical undergraduates and those involved in developing medical undergraduate curricula. Each medical school in the UK, and Trinity College, Dublin were invited to send two participants, one directly involved in nutrition teaching and one directly involved in curriculum development, to a workshop held in Birmingham in November 1995. There were fifty-six participants from twenty-seven of the twenty-eight medical schools invited. All participants were requested to complete a questionnaire before the meeting on the practice in their own medical school, and an assessment form at the end of the meeting.

\section{BACKGROUND TO THE ACTIVITY}

\section{Human nutrition and medical undergraduate teaching}

There had been increasing interest and concern about the teaching of nutrition in the undergraduate medical curriculum for some time. A report published by a British Nutrition Foundation (1983) Task Force focused attention on the importance of nutrition in the training of doctors and the need for a more formal approach than that which was then current. From 1985, appointments at professorial level were made in a limited number of

* M. E. J. Lean, J. S. Garrow, M. Elia, A. Fleck, I. Booth, J. Mathers, A. F. Williams, M. Wiseman, P. Shetty, A. Tomkins, P. Hunt. 
undergraduate medical schools, with a steady increase in the number of senior appointments since 1990.

In November 1990, Professor Garrow's department had organized a meeting on the teaching of nutrition in medical schools with special emphasis on the particular needs in the University of London. In November 1993, Professor Lean's department organized a meeting in Stratford to which representatives from all medical schools in the UK, and Trinity College, Dublin, were invited to discuss the development of nutrition in the undergraduate medical curriculum. From that meeting the need was expressed for a defined group to accept responsibility for carrying the activities forward, and on that basis the creation of the Stratford Executive Group was proposed and subsequently the Group was formed.

At the same time as considerations had been ongoing for the role of nutrition in the undergraduate medical curriculum, the curriculum itself was undergoing most profound and extensive consideration for change. After a wide consultation process the General Medical Council (GMC; 1993) had produced its seminal document, Tomorrow's Doctors, on how undergraduate medical training should be extensively restructured. This change represented but one step in more extensive changes in the structure of the health service, the priorities for delivering health, and the needs for specialist training and continuing education of doctors and other health professionals. Clearly any consideration of the role of nutrition in undergraduate medical training had to take place within the context of the new proposals. For all these reasons, it was considered timely to review the progress which had been made in the development of the undergraduate curriculum in nutrition against the broader background of the fundamental changes taking place in the undergraduate and postgraduate training of clinicians.

\section{Health of the Nation and the Nutrition Task Force}

In 1991, the government's document on its strategy for health in England, The Health of the Nation, was widely circulated for consultation. In response to the consultation process, the Nutrition Society committed its full support in principle and, where possible, in practice.

Following the consultation period in 1992 the Government published the White Paper, The Health of the Nation (Department of Health, 1992). This identified five key areas within which it set quantified targets to reduce deaths and morbidity. In the key area coronary heart disease and stroke these targets were supported by specific nutritional 'risk factor' targets which were to be achieved within the context of a sensible balanced diet, and which have major implications for nutrition in the promotion of health and prevention of disease. The National Nutrition Task Force was set up later in 1992 and following a period of public consultation, in 1994 published Eat Well: An Action Plan from the National Task Force to Achieve the Health of the Nation Targets on Diet and Nutrition (Department of Health, 1994a). Within this action plan there were specific proposals from a working group on the National Health Service (NHS) and Health Service Professionals. One of the three areas identified for action was the creation of a core curriculum in nutrition for health professionals (Department of Health, 1994b). During the same period the report of a Working Party to the Chief Medical Officer for Scotland, The Scottish Diet: Scotland's Health a Challenge to Us All (Scottish Office, 1993), made recommendations of a broadly similar nature for the promotion of health through dietary change in the population. 
The Nutrition Society: education and training

Since the late 1980 s the Nutrition Society has been actively exploring aspects of training and education in nutrition. A report on the training of nutritionists was commissioned from the Institute of Biology and was written by Sir Kenneth Blaxter (1991). Since 1993, and as a part of the activities included in The Health of the Nation (Department of Health, 1992) document, the Nutrition Society had been actively engaged in discussions about the training requirements of nutritionists and the potential for the development of Public Health Nutrition as a cognate discipline in its own right; the explicit objective being to enhance, through appropriate training, professional development and practice of the application of nutrition to human health and well-being. The formation of the SEG, and its proposed involvement with medical training, represented another facet of this developing pattern of activities.

\section{Nutrition in patient care}

Within The Health of the Nation (Department of Health, 1992), great emphasis was placed on health promotion and disease prevention. Nevertheless, nutrition as a discipline goes wider than these public health aspects, and encompasses the nutritional care of patients, both in and out of hospital.

The Nutrition Society first developed a group structure in $1987-8$, with the special needs of the Clinical Metabolism and Nutrition Support Group (CMNSG) playing a catalytic role. Subsequently the CMNSG was instrumental in the creation of the British Association of Parenteral and Enteral Nutrition (BAPEN).

The report from the King's Fund (Lennard-Jones, 1992) on a positive approach to nutrition as treatment, especially for patients in hospital, played a very important role within the NHS in raising the awareness amongst doctors and administrators of the importance of nutritional considerations in patient care. The scientific studies which have enabled progress to be made in the sophisticated nutritional support of seriously-ill individuals have also created a new awareness amongst clinicians of the potential of nutritional management for having profound effects on clinical state and well-being. Publication by BAPEN of authoritative documents on the professional standards needed for nutritional support in the hospital or community environment set standards to be expected for the nutritional understanding of doctors in the future (Elia, 1994; Silk, 1994; Wood et al. 1995).

\section{STRUCTURE OF THE WORKSHOP}

The objectives of the workshop were to:

report on progress in each medical school;

exchange experience;

develop shared materials: curriculum design, approaches to learning, common questions;

develop a bank of clinical cases to illustrate nutrition problems;

identify examples of good practice;

plan activities for the future and identify shared responsibilities to be carried out.

A chairperson and a rapporteur were identified for each of five working groups. The topics for consideration by the five working groups were:

(1) learning materials; 
(2) curriculum structure;

(3) nutrition teaching: skills and structures;

(4) assessment and examinations;

(5) scope of undergraduate exposure, postgraduate training and continuing education.

In advance of the workshop, the chairperson for each group was requested to prepare a draft working paper of 2000 to 3000 words on the specified topic for their own group. The papers were circulated to all chairpersons and rapporteurs before the meeting and were available for all participants at the meeting. The papers were then used as background documents to help structure discussions within each working group.

\section{CONDUCT OF THE WORKSHOP}

Each of the working groups developed their conclusions and/or recommendations. Following the workshop, the draft working papers were revised and finalized by the chairpersons with the agreement of the participants. The summaries and conclusions from these papers are set out below and copies of the complete papers in the full report are available from the Nutrition Society.

Working Group 2, in considering the curriculum structure came to the conclusion that within any of the approaches adopted, the place for nutrition can be defined for each medical school and may differ widely from one school to another. Regardless of the place or the approach used, there are certain key elements which the student should possess by the end of the undergraduate experience. In Working Group 3, the conclusion was reached that, although nutritionists should have overall responsibility for the content and standards in nutrition training of medical undergraduates, because nutrition impacts across a wide range of disciplines, there is no single individual or group who possesses unique responsibility for delivering the teaching, or communicating the wide interactions and relevance of nutrition. There is a need to take best advantage of professionals with specialist skills, whilst having an identified focus of responsibility for drawing the threads together, ensuring cohesion within each medical school, and ensuring that the minimum standards for training in Human Nutrition are achieved.

Working Groups 1 and 4 addressed the problem of the availability of and the need for suitable materials for learning on the one hand and assessment on the other. Each of these represents a substantial task. If the work is to be done well and to an appropriately high standard, there is the need to draw as effectively as possible on the available resources, nationally and internationally. The time has now come when it is most cost effective for this to be done in an organized and structured way. Benefit would accrue to all if there was an adequately supported national programme, under collective ownership, but with a centralized reference centre.

Each working group identified the past error of overloading the undergraduate experience, in terms of information and the level of skills and understanding expected. The advantages of defining the limits of the expectations for undergraduates were emphasized repeatedly. However, any limitation at the undergraduate level would demand the availability of the opportunity to develop experience and abilities at a later stage. Working Group 5 emphasized the need for continued and further work in the development of appropriate postgraduate and continuing educational opportunities.

The feedback from the participants in their assessments of the workshop indicated a high 
level of satisfaction. Many considered that real progress had been made, and most were certain that there was shared benefit in there being some form of continuing activity on a regular, ongoing basis. The participants in the workshop acknowledged that the Nutrition Society had played a seminal role in fostering the SEG as part of its commitment to support the Health of the Nation. The participants outlined four strategies for the support of the promotion of nutrition in the medical curriculum:

individual and collective assistance for medical schools in the process of developing the new undergraduate curriculum, to help them identify the most suitable ways in which nutrition can be used as a thread for both vertical and horizontal integration into the course; the development of more suitable materials for use in learning and in the assessment of clinicians at both the undergraduate and postgraduate stages of their education;

the firm establishment of nutrition as a discipline of direct and important relevance for the promotion of health, prevention of disease and the treatment of individual patients; through the contribution of its science, its application in clinical care and its direct contribution to the creation of a healthier lifestyle;

the creation of postgraduate training opportunities in the public health, community and clinical settings.

\section{CONCLUSIONS AND/OR RECOMMENDATIONS FROM THE WORKING GROUPS}

\section{Working Group 1: learning resources}

Effective learning can only be achieved with learning resources that take into account the specific needs of the medical undergraduate. In order to support the learning process, there is a need to:

establish a national programme to: (1) identify, register and distribute resources, (2) develop new resources to meet the defined needs;

establish a steering group to take responsibility for the activity;

encourage a professional grouping to take collective ownership of the activity;

ensure ongoing evaluation and development of materials within the programme;

create an infrastructure to support the programme which requires: (1) a centralized resource to serve as the hub of this network, (2) a dedicated coordinator to be responsible for the programme, (3) financial support to cover the costs of setting up the infrastructure, ongoing staffing and administrative costs, and costs of production associated with the development and supply of resource materials.

\section{Working Group 2: curriculum structures}

There is no single solution to the tasks of developing competence or increasing awareness and understanding of Human Nutrition in the Medical Undergraduate Education and Training.

Human Nutrition can be incorporated as a 'vertically' integrative theme, to link Basic Sciences, Clinical and Public Health aspects of health and disease in the core curriculum.

Human Nutrition offers the potential of 'horizontal' integration as a component of Problem-Based approaches.

There may be value in single courses in Human Nutrition to complement thematic learning.

Human Nutrition is well suited to Special Study Modules, particularly for Public Health 
Nutrition.

'Starter Lists' are offered of Learning Objectives and Special Concepts in Human Nutrition.

\section{Working Group 3: nutrition teaching: skills and structures}

All medical schools should be made aware of the Nutrition Core Curriculum (Department of Health, 1994b) document and further copies should be sent to medical schools for consideration by the Curriculum Committee.

Each medical school should appoint a senior faculty member to the position of Nutrition Coordinator on the Curriculum Committee. This should be a permanent position which will be maintained when the original appointee leaves.

Medical practitioners should have a basic level of competence in nutrition which is integrated with and applied to other clinical knowledge. Teaching of nutrition should draw widely on available skills across disciplines, including dietetics.

Nutrition should be promoted as a 'model' subject for vertical and horizontal teaching throughout the course and the nutrition being taught should be relevant to what a doctor needs to know.

Nutritional topics and questions should be included in the student logbooks for the clinical course and in the assessment process.

\section{Working Group 4: assessment and examinations}

Tasks for the future:

the existing set of nutrition multiple-choice questions (MCQ) should be further refined and extended, and their performance in assessing nutrition knowledge among medical students should be assessed;

the University of London (and others who use only the 'single correct response' format) should be pressed to adopt more flexible and powerful formats for MCQ;

composition of nutrition MCQ (with expert supervision) is a valuable project for senior medical students; this would have the effect of providing more questions, and also providing formative assessment of the students' understanding;

Objective, Structured Clinical Examinations (OSCE) and special subject modules should be devised to improve the assessment of attitudes and skills in nutrition, and also to help to integrate nutrition learning with other aspects of medicine;

it would be helpful to have an agreed procedure (including history and physical examination) for clinical screening of the nutritional status of patients. This should be part of any routine examination, for example when 'clerking' a patient on admission;

Continuing Medical Education (CME) should be used to make many groups of health professionals more nutrition-literate, so they would be better able to contribute to the teaching and assessment of nutrition. It is encouraging that Nutrition Society meetings are now recognized for $\mathrm{CME}$ credits.

\section{Working Group 5: from undergraduate to postgraduate education and training}

Undergraduates. Undergraduate medical training should establish an appreciation of the breadth of nutrition and the appreciation that most health problems have a nutritional component;

the training should have clinical and personal relevance. 
Postgraduates. Postgraduate training in nutrition should be established at the same time as undergraduate training, so that there is a continuum between the two; postgraduate training should be targeted to at least three specific groups of health professionals: general practitioners; hospital-based health professionals; and public health nutritionists;

the training should lead to an appreciation that nutrition training is an important part of all clinical training.

Nutrition as a speciality. Nutrition should be recognized as a medical speciality, and this recommendation should be formally supported and promoted by the Royal Colleges.

Implementation of these recommendations will lead to:

structured nutrition training by various educational and clinical departments; improved structure of nutrition services;

a focus of nutrition in clinical practice.

The Stratford Executive Group would like to acknowledge the following for their support in organizing this workshop: The Nutrition Society, Department of Health, Health Education Authority, Cow and Gate/Nutricia, Kellogg Company of Great Britain, The Rank Prize Funds.

\section{REFERENCES}

Blaxter, K. (1991). Training Nutritionists: A Report for the Nutrition Society by the Institute of Biology. London: Institute of Biology.

British Nutrition Foundation (1983). Nutrition in Medical Education: Report of the BNF Task Force on Clinical Nutrition. London: British Nutrition Foundation.

Department of Health (1992). The Health of the Nation: A Strategy for Health in England. London: H.M. Stationery Office.

Department of Health (1994a). Eat Well: An Action Plan from the Nutrition Task Force to Achieve the Health of the Nation Targets on Diet and Nutrition. London: Department of Health.

Department of Health (1994b). Core Curriculum for Nutrition in the Education of Health Professionals. London: Department of Health.

Elia, M. (1994). Enteral and Parenteral Nutrition in the Community. Maidenhead, Berks.: British Association of Parenteral and Enteral Nutrition.

General Medical Council (1993). Tomorrow's Doctors: Recommendations on Undergraduate Medical Education. London: General Medical Council.

Lennard-Jones, J. E. (editor) (1992). A Positive Approach to Nutrition as Treatment. London: King's Fund Centre.

Scottish Office (1993). The Scottish Diet: Scotland's Health a Challenge to Us All. Edinburgh: The Scottish Office.

Silk, D. B. A. (1994). Organisation of Nutritional Support in Hospitals. Maidenhead, Berks.: British Association of Parenteral and Enteral Nutrition.

Wood, S., Shaffer, J. \& Wheatley, C. (1995), Home Parenteral Nutrition: Quality Criteria for Clinical Services and the Supply of Nutrients Fluids and Equipment. Maidenhead, Berks.: British Association of Parenteral and Enteral Nutrition. 